\title{
INHIBITION OF SERUM NAPHTHYLAMIDASES BY ATOPIC ALLERGENS
}

\section{BERRENS}

Department of Dermatology, Section Biochemistry of the Skin, Academic Hospital, Utrecht (The Netherlands)

(Received May 15, 1 968)

SUMMARY

Human serum hydrolyses the 2-naphthylamides of L-lysine and L-arginine. The enzymatic activity of the serum naphthylamidases is inhibited by atopic allergens and by protein-sugar conjugates carrying I-deoxy-2-ketose residues attached to the $\varepsilon$-amino groups of lysine residues in their peptide moieties. The inhibiting capacity of these substances was found to be directly related to the number of sugar-linked lysine residues in the molecular framework. The sensitivity spectrum of the serum naphthylamidases towards other modifiers indicates these enzymes to be identical with, or closely related to serum leucine aminopeptidase. No difference was detected in the behavioural pattern of these enzymes from the sera of allergic patients with regard to inhibition by allergens. It is suggested that the inhibitory action of atopic allergens may, as a side-effect, impair the ability of allergic individuals to inactivate lysyl-bradykinin (kallidin) generated in response to the initial allergen-reagin interaction.

\section{INTRODUCTION}

Atopic allergens are the biologically active substances eliciting the clinical symptoms of asthma, hay fever or atopic dermatitis in predisposed ("atopic") and sensitized human allergic individuals. Many of these allergens have been demonstrated to incorporate I-denxy-2-ketoses conjugated in position I to the $\varepsilon$-amino groups of lysine residues in the molecular framework of protein or glycoprotein carriers; evidence has been presented for the participation of these particular lysyl-sugar residues in the elicitation of positive (wheal and flare) reactions during skin tests in atopic patients ${ }^{1}$.

The present report deals with the action of atopic allergens and some relevant model compounds upon enzymes cleaving $\mathrm{N}$-terminal lysine residues. This subject seemed of particular interest because this type of enzyme is involved in the physiological breakdown of the vasodilating and smooth muscle-stimulating decapeptide kallidin, which has becn implicated to arise in response to the initial trigger of the allergen-antibody ("reagin") interaction in epithelial tissues.

A number of different enzymes are known to inactivate the kinins kallidin 
and bradykinin; among these the "converting enzyme" aminopeptidase B, described by Hopsu-Havu et al ${ }^{2,3}$ and the kininase carboxypeptidase $\mathrm{N}$, discovered by Erdös and coll. ${ }^{4,5}$ are the most intriguing. Aminopeptidase has been reported specific for N-terminal lysine and arginine residues; the enzyme converts kallidin into the nonapeptide bradykinin without attacking the N-terminal arginine-prolyl bond of bradykinin ${ }^{3}$. Erdös et al. believe bradykinin to be subsequently inactivated by carboxypeptidase $\mathrm{N}$, which cleaves the C-terminal arginine; des $\left(\arg ^{\mathrm{I}}\right)$-bradykinin and des(arg')-bradykinin are both inactive in biological assay. There is some evidence that activated plasma- or tissue kallikreins act upon an $\alpha_{2}$-globulin substrate to release kallidin first, which must be converted into bradykinin before the pharmacological activity can be completely abolished ${ }^{6}$.

It has been considered for some time that the release and/or blockade of enzymatic activity is one of the essential features of the allergic reaction? No investigations are on record concerning the direct interaction of atopic allergens and enzyme systems. As a first approach the influence of these allergens upon serum aminopeptidases will be reported here.

\section{METHODS}

For the assay of aminopeptidase activity in human sera use was made of known methods for estimating naphthylamidases. According to Arturson et al. ${ }^{8}$, there exist at least three isvenzymes of leucylnaphthylamidase in human serum, designated A, $\mathrm{B}$ and $\mathrm{C}$ according to their position in starch gel electropherograms. The term serum naphthylamidases will be endorsed here.

Substrates for enzyme assay included L-lysyl-2-naphthylamide carbonate, Larginyl-2-naphthylamide $\mathrm{HCl}$ (Mann Research Labs), and L-leucyl-2-naphthylamide $\mathrm{HCl}$ (Schuchardt). The reaction mixture consisted of $2.0 \mathrm{ml}$ Tris (hydroxymethyl) aminomethane- $\mathrm{HCl}$ buffer, O.I $M, \mathrm{pH} 7.0$, incorporating quantities of up to I $\mathrm{mg}$ of allergen or modifier, to which was added $0.2 \mathrm{ml}$ of freshly prepared substrate solution (0.2 $\mu$ mole) and $0 . \mathrm{I} \mathrm{ml}$ of human serum. The tubes were shaken for $\mathrm{I} h$ at $37^{\circ}$, and the reaction was stopped by the addition of I $\mathrm{ml}$ o.I \% Fast Garnet GBC Salt in I $M$ sodium acetate buffer $\mathrm{pH} 6.5$. After standing for $3^{\circ} \mathrm{min}$ at room temperature, the extinction of the samples was read at $525 \mathrm{~nm}$. Blanks were included for enzyme (serum) and reagent absorption, for allergen absorption at $525 \mathrm{~nm}$, and for spontaneous substrate decomposition. A standard (in duplicate, no allergen added) was included in each set of determinations and results were read on a calibration curve constructed separately with cryst. $\beta$-naphthylamine- $\mathrm{HCl}$.

Methods for the determination of protein nitrogen (micro-Kjeldahl), total hexoses, and "available" lysine have been given in previous publications ${ }^{1,9,12-14}$. Ultraviolet absorption spectra of allergens and model compounds were observed in the Zeiss PMQ II spectrophotometer, applying solutions in 0.0 I $M$ phosphate buffer $\mathrm{pH}$ 7.0 and I-cm cells unless otherwise stated.

MATERIALS

Pooled sera of a large number of normal donors were used for most experiments. Sera of allergic individuals were obtained from atopic patients with immediate type 
wheal and flare reactions to the intracutaneous administration of house dust and human dandruff allergen (o.I "percent" commercial extracts, o.I ml).

Table I lists the allergens and fractions of allergenic extracts employed, together with some pertinent analytical characteristics and estimates of their specific activity in skin tests. The allergens were isolated as before and details of the isolation procedure for each fraction may be retrieved by their respective codes from the references in Table I.

\section{TABLE I}

SOME ANALYTICAL DATA OF THE ALLERGENS AND FRACTIONS FROM ALLERGENIC EXTRACTS USED IN THIS INVESTIGATION, TOGETHER WITH ESTIMATES OF THEIR RELATIVE SPECIFIC ACTIVITIES BY DIRECT SKIN TEST IN SPECIFICALLY HYPERSENSITIVE ATOPIC PATIENTS

\begin{tabular}{|c|c|c|c|c|c|c|c|}
\hline Allergen & Code & $\begin{array}{c}(a) \\
E_{I}^{I} \mathrm{~cm} \\
305 \mathrm{~nm}\end{array}$ & $\begin{array}{c}(a) \\
E_{I \%} \% \\
280 \mathrm{~cm}\end{array}$ & $\lambda_{0}(b)$ & $\begin{array}{c}\text { (c) } \\
0 \\
\text { Hexoses }\end{array}$ & $\begin{array}{c}\text { (d) } \\
\text { Spec. act. } \\
\text { units/mg }\end{array}$ & Ref. \\
\hline Kapok & $\mathrm{KP}-\mathrm{C}$ & I 50.0 & I 76.0 & 2.0 & $34 \cdot 4$ & $75^{\circ}$ & 9 \\
\hline Liquorice & $\mathrm{SI}-\mathrm{F}$ & I I.OO & $\mathrm{I}_{4} .02$ & $3 \cdot 3$ & $34 \cdot 4$ & 500 & IO \\
\hline Feathers & FE-B & $43 \cdot 3$ & 58.0 & $4 \cdot 5$ & 2.7 & I 6000 & I I \\
\hline House dust & $\mathrm{HE}-\mathrm{B}$ & 33.0 & 44.0 & 10.9 & 8.1 & 430 & I 2,13 \\
\hline House dust & $\mathrm{HE}-\mathrm{D}$ & 42.4 & 57.3 & 9.7 & 13.7 & 7250 & I 2,13 \\
\hline House dust & $\mathrm{HE}-\mathrm{E}$ & 8.12 & 13.60 & 8.0 & $3 \mathbf{I} \cdot \mathbf{I}$ & 345000 & I 2,13 \\
\hline Human dandruff & HD-B & 8.08 & 10.88 & $9, \mathrm{I}$ & I. 2 & & $\mathrm{I}_{4}$ \\
\hline Horse dandruff & $\mathrm{HOD}$ & $4 \cdot 4^{8}$ & 10.36 & I 0.2 & & TOOOO & I 5 \\
\hline Timothy grass pollen & $\mathrm{GP}-4$ & 2.50 & $5 \cdot 40$ & T I. 9 & To. 8 & 5000 & I 6 \\
\hline Oromucoid & $\mathrm{OVO}$ & 0.38 & 4.24 & I 3.2 & 6.9 & 400000 & I 7 \\
\hline
\end{tabular}

(a): in phosphate buffer, o.or $M, \mathrm{pH}, 7.0$.

(b) : by micro-Kjeldahl.

(c): as \% galactose in the orcinol test.

(d) : for definition see ref. I 2 .

Known enzyme inhibitors included ovomucoid (trypsin inhibitor type 11-o from egg white, Sigma Chem. Corp.), which is also an allergen ${ }^{17}$, soy bean trypsin inhibitor (SBTI, chromatographic component VI, Mann Res. Labs.) and the kallikrein inhibitor from bovine lung (Trasylo ${ }^{\mathbb{B}}{ }^{2}$, Bayer). Ovalbumin-glucose and ovalbumin-ribose conjugates incorporating sites of (lysyl)- $\varepsilon$-amino-linked sugar were prepared as before ${ }^{16,18}$ by heating $0.5 \%$ sterile solutions of $3 \times$ crystallized ovalbumin (ovomucoid-free) containing $2 \% \mathrm{D}$-ribose or $20 \% \mathrm{D}$-glucose at $50^{\circ}$ for various periods of time (up to $\mathrm{I} 6 \mathrm{o}$ h), followed by dialysis against distilled water and recovery of the modified protein by lyophilization; a series of control proteins were obtained by similar treatment in the absence of sugar. Conjugates of crystalline bovine serum albumin and $\mathrm{D}$-ribose or $\mathrm{D}$-arabinose (BSAR and BSAA) were prepared in a similar fashion.

The low-molecular weight model compound $N$ (I-deoxy-I-D-fructosyl)- $\varepsilon$ aminocaproic acid (EACAF) was synthesized from $\varepsilon$-aminocaproic acid (EACA) and $\mathrm{D}$-glucose as before ${ }^{19}$. Isoxazole was synthesized from malonaldehyde bis (dimethylacetal) (Aldrich Chem.) and hydroxylamine by the method of Justoni ${ }^{20}$.

\section{RESULTS}

\section{a. Some enzyme characteristics}

Human serum hydrolyses the 2-naphthylamides of the basic amino acids 
L-arginine and L-lysine. The ratio of leucyl-, arginyl-, and lysyl-naphthylamidase activity was found to be $32: 19: 10$, or roughly $3: 2: 1$. The mean level of arginylnaphthylamidase in human sera amounts to $\mathrm{I} 9.0 \mu \mathrm{mole} / \mathrm{min} / 1$ and of lysyl-naphthylamidase to ro.5 $\mu \mathrm{mole} / \mathrm{min} / 1$; no significant differences exist in the level of these enzymes between sera of normal and allergic individuals ${ }^{21}$.

The hydrolysis of L-lysyl- and L-arginyl-2-naphthylamide by human serum was studied more closely for evaluating some essential parameters. The rate of hydrolysis of both substrates proved to be a linear function of serum concentration up to a volume of $0.12 \mathrm{ml}$ added to the standard test system (METHODS section). At the serum concentration routinely employed, the reaction velocity increased in proportion to substrate concentration up to $0 . I \mu$ mole in the incubation medium, at which point the reaction progressed at maximum velocity; for routine assays, an excess amount of $0.2 \mu$ mole was found adequate. Substrate decomposition by serum naphthylamidases was $90-95 \%$ complete in I h at $37^{\circ}$, which was considered satisfactory for a standard procedure.

A preliminary attempt was made to concentrate the specific lysyl- and arginylnaphthylamidase from normal serum by localizing enzyme activity in fractions collected from serum samples sieved through columns of Sephadex G-20o. In these experiments, $7 \mathrm{ml}$ of serum, dialysed ovcrnight against $0 . \mathrm{I} M$ Tris- $\mathrm{HCl}$ buffer $\mathrm{pH} 7.0$, was applied to a column $(80 \times 3 \mathrm{~cm})$ of Sephadex $\mathrm{G}-200$, suspended in and subsequently eluted with the same buffer solution. Fractions of $5 \mathrm{ml}$ were collected automatically at Io-min intervals and analysed continuously for u.v. absorption at $254 \mathrm{~nm}$. Leucyl-, lysyl- and arginyl-naphthylamidase activity was determined in 0.5 - $\mathrm{ml}$ aliquots of each fraction. A typical protein and enzyme distribution pattern has been reproduced in Fig. $I$.

The naphthylamidase activity specific for each substrate was eluted in almost exactly the same position, the bulk of the enzyme activity being associated with proteins of the $\beta$ - and $\alpha$-globulin class; the minor peak in the $7 \mathrm{~S}$ immunoglobulin

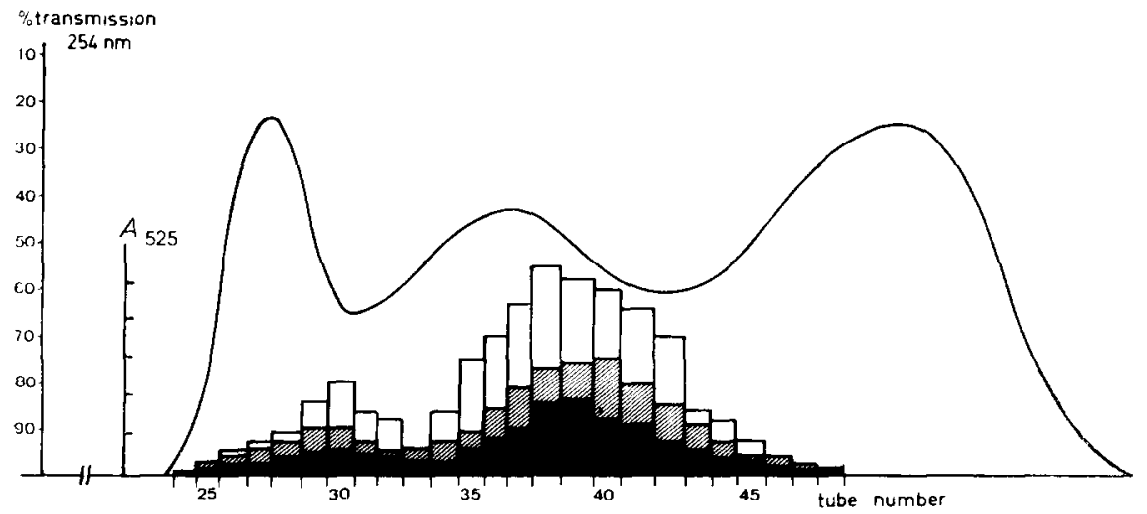

Fig. I. Chromatography of pooled normal human serum $(7 \mathrm{ml})$ on a column $(80 \times 3 \mathrm{~cm})$ of Sephadex $\mathrm{G}-200$ in $0 . \mathrm{I} M$ Tris-HCI buffer $\mathrm{pH} 7.0$ and eluted with the same buffer. Volume collected in each tube: $5 \mathrm{ml}$. Percent transmission at $254 \mathrm{~nm}$ indicates position of eluted proteins. Columns under the curve show position of leucyl-(white columns), arginyl-(hatched columns) and lysyl(black columns) naphthylamidase activity assayed under identical conditions (METHODS section) and arbitrarily expressed in absorbance units at $525 \mathrm{~nm}$. 
region may perhaps be attributed to aspecific hydrolysis mediated by proteases or esterases eluted in this range.

A dialysed pool of fractions $33-44$ from 5 separate Sephadex filtrations, upon lyophilization, yielded 7ro $\mathrm{mg}$ of an easily soluble enzyme preparation from $35 \mathrm{ml}$ of serum. The properties of this enzyme sample were identical to those from whole serum; I $\mathrm{mg}$ of the preparation, in the presence of $0.002 \mathrm{M} \mathrm{MgCl}_{2}$, hydrolysed the 2-naphthylamides of L-leucine, L-arginine and L-lysine in the ratio of $3: 2: \mathrm{I}$ and at

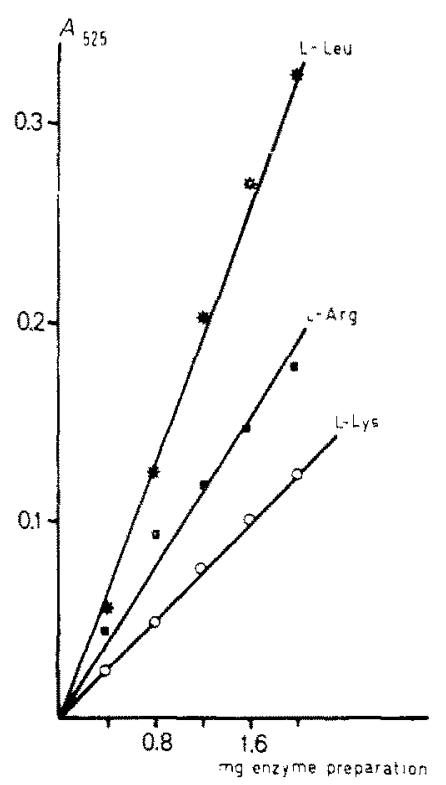

Fig. 2. Hydrolysis of L-leucyl-, L-arginyl- and L-lysyl-2-naphthylamides by different quantities of partially purified naphthylamidase pool isolated by Sephadex $G-200$ column chromatography of normal human serum (compare Fig. $I$, fractions 33-44). Substrate concentrations: $0.2 \mu M$ in the standard test system (see METHons section).

about the same rate as observed with $0 . \mathrm{I} \mathrm{ml}$ of serum (Fig. 2). The pattern of inhibition of the purified enzyme sample by allergens and other modifiers (RESULTS, sections $b$ and c) did not differ from that observed with whole serum.

\section{b. Inhibition by atopic allergens}

All allergens investigated were found to inhibit the naphthylamidase in both normal and allergic sera. The inhibiting capacity of any particular allergen depended on the nature of the substrate, allergens being less potent inhibitors of leucyl-2naphthylamide hydrolysis than of the enzymatic decomposition of the 2-naphthylamides of the two basic amino acids. Because of the possible identity of the lysylnaphthylamidase enzyme to aminopeptidase B involved in the breakdown of kallidin (see INTRODUCTION), most studies were devoted to the interference of atopic allergens with the enzymatic cleavage of the lysyl-2-naphthylamide substrate molecule.

In order to establish a comparative scale of the inhibiting capacities of distinct allergens, five different allergen concentrations were employed in each case in the 


\section{TABLE II}

INHIBITING CAPACITY OF SOME ATOPIC ALLERGENS AND FRACTIONS OF ALLERGENIC EXTRACTS, TOGETHER WITH SOME ESSENTIAL PARAMETERS FOR ESTIMATING THE MEAN NLMBER OF BLOCKED LYSINE RESIDUES IN THEIR PEPTIDE PORTIONS (see text)

\begin{tabular}{|c|c|c|c|c|}
\hline Allergen & Code & $\begin{array}{l}E_{305} / E_{280} \\
\text { corr. }\end{array}$ & $\begin{array}{l}I_{25} \\
(\mathrm{mg} / O . I \mathrm{ml} \\
\text { of serum) }\end{array}$ & $\begin{array}{l}\% \text { Available } \\
\text { lysine }\end{array}$ \\
\hline Kapok & $\mathrm{KP}-\mathrm{C}$ & 2.68 & 0.3 & 0.07 \\
\hline Liquorice & SL-F & 2.20 & o. I & \\
\hline Feathers & IFE-B & 1.92 & 0.8 & 0.23 \\
\hline House dust & HE-B & 1.75 & 0.5 & o.I 2 \\
\hline Housc dust & IIE-D & I.87 & $2 . \mathrm{I}$ & 0.22 \\
\hline House dust & HE-E & 1.22 & 0.7 & 0.29 \\
\hline Human dandruff & $\mathrm{HD}-\mathrm{B}$ & 1.92 & I. 3 & \\
\hline Horse dandruff & HOD & 0.67 & 3.8 & 0.83 \\
\hline Timothy grass pollen & $\mathrm{GP}^{\mathrm{P}}-4$ & 0.75 & 1.3 & $5 \cdot 4^{\circ}$ \\
\hline Ovomucoid & OVo & 0.09 & 2.8 & \\
\hline
\end{tabular}

$\mathrm{l}_{25}=$ dose in $\mathrm{mg}$ for $25 \%$ inhibition of lysyl-2-naphthylamide hydrolysis by $0 . \mathrm{I} \mathrm{ml}$ of pooled normal human serum in the standard test system (METHODs section).

standard test system, and the results were plotted in dose-inhibition curves. The quantity of allergen required for $25 \%$ inhibition was read from these curves by in trapolation, the reference point being chosen at $25 \%$ inhibition so as to enable a confrontation with the effect of the less potent protein-sugar model conjugates (REsults, section c). The $I_{25}$-values of different atopic allergens have been listed in Table II.

Also included in Table II are the corrected values of the ratio of extinction cuefficients $E_{305} / E_{280}$ for each separate allergen as a rough estimate of the meanl Ilumber of lysyl-sugar residues in the allergen molecules. It has been found that the absorption of radiation at $305 \mathrm{~nm}$ in the $u . v$. spectrum of atopic allergens and protein-sugar model conjugates is indicative of the $\mathrm{I}, 2$-enol form of the I-deoxy-2-ketose residue attached at C-I to the $\varepsilon$-amino function of lysyl residues in the peptide moieties ${ }^{16,18,22}$. The $E_{305} / E_{280}$ ratio in the absorption spectrum of the relevant low-molecular weight model compound EACAF (METHODS section) was found to be I.2I (ref. I9), meaning that $280 \mathrm{~nm}$ absorption in the spectrum of allergens includes a contribution by the descending leg of the lysyl-sugar chromophore. In consequence, the extinction coefficients at $280 \mathrm{~nm}$ of atopic allergens require a correction factor $\left(\mathrm{E}_{280}=E_{280}\right.$ observed $\left.E_{305} \times 0.82\right)$ for a closer estimate of the peptide content of the allergens. It can easily be shown with the aid of model conjugates ${ }^{1}$ that there exists an inverse relationship between these corrected $E_{305} / E_{280}$ values and the percentage of "available" lysine (i.e., the number of lysine- $\varepsilon$-amino groups free to react with 2,4 -dinitrofluorobenzene). These considerations justify the employment in Fig. 6 of the corrected $E_{305} / E_{280}$ values of allergens and protein-sugar model conjugates as estimates of the number of blocked lysine residues in the peptide portions of these molecules.

\section{c. Inhibition by model compounds}

The role of the lysyl-sugar residue in the inhibition of serum lysyl-naphthylamidase by atopic allergens was studied in more detail with the aid of a series of wellcharacterized ovalbumin-aldose conjugates incorporating established and increasing proportions of blocked lysine residues. 
TABLE III

INHIBITING CAPACITY $\left(\mathrm{I}_{25}\right)$ OF SOME SYNTHETIC MODEL COMPOUNOS, TOGETHER WITH SOME RELEVANT ANALYTICAL CHARACTERISTICS

\begin{tabular}{|c|c|c|c|c|c|c|c|c|c|}
\hline Model compound & $\begin{array}{l}\text { Reac } \\
\text { honon } \\
\text { period, } \\
h \\
\text { (a) }\end{array}$ & Code & $\begin{array}{l}E_{I}^{I \%} \mathrm{~cm} \\
305 \mathrm{~nm} \\
(c)\end{array}$ & $\begin{array}{l}E_{10 \%}^{x \mathrm{~cm}} \\
280 \mathrm{~mm} \\
\text { (c) }\end{array}$ & $\begin{array}{l}E_{305} / E_{280} \\
c 8 \% \%\end{array}$ & $\begin{array}{l}\% \\
\text { Hevoses } \\
\text { (d) }\end{array}$ & $\begin{array}{l}\% \\
\text { Avait. } \\
\text { bysine }\end{array}$ & $\begin{array}{l}\text { Mean } \\
\text { no. of } \\
\text { blockad } \\
\text { lysines } \\
\text { pey wole } \\
\text { (e) }\end{array}$ & $\begin{array}{l}l_{25} \\
m g 10 . T \\
m b\end{array}$ \\
\hline \multirow[t]{5}{*}{ Ovalb.-ribose conj. } & 16 & OVR-a & 3.20 & I 1.6 & 0.27 & 1.95 & $3 \cdot 55$ & 9 & $7 \cdot 3$ \\
\hline & 24 & OVR-b & 4.20 & 12.6 & 0.35 & 2.10 & 2.90 & II & 5.9 \\
\hline & $4^{\circ}$ & OVF-c & 6.10 & 14.0 & $0.5 \mathrm{I}$ & 2.10 & 2.15 & $I_{3}$ & 3.9 \\
\hline & 64 & OVR-d & 13.80 & 22.8 & I.I5 & I. 85 & 1.65 & $I j$ & 2.2 \\
\hline & 88 & OVR-e & 16.20 & 26.4 & 1.35 & 2.10 & 0.95 & 17 & 1.2 \\
\hline Ovalb.-glucose conj. & 160 & $O V G-p$ & 6.20 & 16.2 & $0.5^{2}$ & 2.50 & $2.8 j$ & II & $5 \cdot 4$ \\
\hline Controls ovalbumin $(b)$ & $16-760$ & OVi-k & 1.30 & 12.8 & 0.10 & 1.70 & $0.30(t)$ & 0 & $>10$ \\
\hline Controls BSA $(b)$ & $4^{8}$ & $\mathrm{BSA}$ & 0.59 & 5.9 & 0.10 & & & & $>10(g)$ \\
\hline BSA-ribose conjugate & 24 & BSAR & 2.40 & 7.0 & 0.47 & & & & 1.3 \\
\hline BSA-arabinose conj. & 3 & BSAA-a & 1.32 & 6.0 & 0.22 & & & & 5.8 \\
\hline BSA-aralinose conj. & $4^{8}$ & $B S A A-b$ & 2.78 & 8.4 & 0.47 & & & & 1.8 \\
\hline$\varepsilon$-Aminocaproic acid & & EACA & & & & & & & 3.1 \\
\hline $\begin{array}{l}N(\text { I-deoxy-I-D-fructo- } \\
\text { syl) } \varepsilon \text {-aminocaproic ac, } \\
\text { Isoxazole }\end{array}$ & & EACAF & (h) & $(h)$ & I. 21 & & & & $\begin{array}{l}0.2 \\
1.0(i)\end{array}$ \\
\hline f-Aminovaleric acid & & $\mathrm{DAV}$ & & & & & & & 2.9 \\
\hline
\end{tabular}

(a): figures in this column give the number of hours allowed for the interaction of cryst. ovalbumin and the aldose in aq. solution at $50^{\circ}$ before isolation of the protein-sugar conjugate; $(b)$ heated under identical conditions but in the absence of sugar; (c): in o.I $M$ phosphate buffer $\mathrm{pH} 7.0$; (d): as \% galactose in the orcinol test:; note that monosaccharide residues attached to protein- $\varepsilon$-amino groups by Maillard reaction cannot be detected by the classical orcinol or anthrone reaction, $c f$. ref. 16 and $22 ;(e)$ : values rounded off to the nearest whole number; (f) native ovalbumin encompasses 20 lysine residues per mole of protein; ( $g$ ) calculated per half molecule $(65400 / 2) ;(h)$ not known exactly because the compound is extremely hygroscopic; $(i)$ : in $\mu$ l.

Some high-molecular weight conjugates prepared with bovine serum albumin as the starting material, and a few low-molecular weight model compounds were also employed. The pertinent analytical data have been assembled in Table III.

The high-molecular weight protein-sugar models incorporating $N$-glycosidically linked sugar residues were found to inhibit the serum naphthylamidases, the inhibiting capacity being directly related to the extent of sugar conjugation. The inhibitory action of these models must be due to the lysyl-sugar determinants because the partial thermal denaturation of the protein partner during synthesis of the conjugates did not confer inhibitory properties onto the molecule: the control proteins heated in the absence of sugar (Table III) did not impair enzymatic cleavage of the naphthylamide substrates.

As an example, Fig. 3 gives the dose-inhibition curves established with a series of ovalbumin-ribose conjugates (Table III); the $\mathrm{I}_{25}$-values for individual members of the series were computed from these graphs by intrapolation.

The ovalbumin-glucose conjugates synthesized during analogous periods of reaction at $50^{\circ}$ (METHODS section) proved to be less effective inhibitors than the corresponding ovalbumin-ribose complexes; presumably, this result is attributable to the lower degree of sugar attachment in the former: glucose is known to be a far less aggressive partner than ribose during non-enzymatic browning reactions with protein or amines. Of the series of ovalbumin-glucose conjugates prepared, the in- 

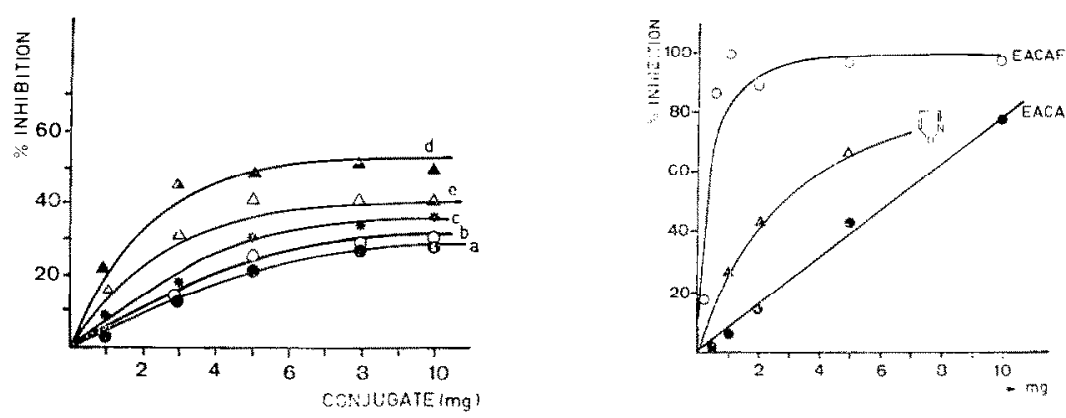

fig. 3. Percent inhibition under standard conditions of lysyl-2-naphthylamide hydrolysis (0.2 $\mu$ mole) by $0.1 \mathrm{ml}$ of normal human serum due to the presence of different quantities of synthetic ovalbumin-ribose conjugates incorporating increasing proportions of $\mathrm{I}$-deoxy-z-ketose residues attached to (Jysyl)- $\varepsilon$-amino groups (models OVR-a to OVR-e, Table III).

Fig. 4. Percent inhibition under standard conditions of lysyl-z-naphthylamide hydrolysis (o.2 $\mu$ mole) by $0.1 \mathrm{ml}$ of normal human serum due to the presence in the assay mixture of increasing amounts of $N(\mathrm{I}$-deoxy-I-D-fructosyl) $\varepsilon$-aminocaproic acid (EACAF), $\varepsilon$-aminocaproic acicl (EACA) or isoxazole.

hibiting capacity of only one member (OVG-p, Table III) was sufficiently high to warrant a reliable estimate of the $I_{25}$-value. The $I_{25}$-values of a number of model conjugates, established under standard assay conditions, have been included in Table III.

The results obtained with these model compounds provided reasonable evidence for the direct participation of the lysyl-sugar determinants in the process of serum naphthylamidase inhibition. This conclusion was further substantiated by experiments using the low-molecular weight model $N$ (I-deoxy-I-D-fructosyl)- $\varepsilon$-aminocaproic acid (EACAF), which proved a more powerful inhibitor than the parent compound EACA (Fig. 4), or than $\delta$-amino-n-valeric acid.

Interestingly, the organic liquid isoxazole was found capable of suppressing the action of lysyl-naphthylamidase (Fig. 4); the compound is structurally related to the pseudo-isoxazoline configuration proposed to be one of the stabilized forms of the 2,3-enediol tautomer of the $I$-deoxy-2-ketose residue attached to the lysine $-\varepsilon$-amino groups in atopic allergens ${ }^{19}$.

In an attempt to discover a relationship between the inhibiting capacity of individual allergens or high-molecular weight model conjugates, and the number of sugar-linked lysine residues in the molecular framework, the $\mathrm{I}_{25}$-values evaluated experimentally were plotted versus the $E_{205} / E_{280}$ ratios as the only though not idealestimates of the number of blocked lysine residues accessible at present. Since the molecular weights of diverse atopic allergens are considered to be of the same order of magnitude ( $M$ about 20-10000, ref. 23), which approaches the range of the ovalbumin-aldose conjugates ( $\mathrm{M}$ about 45000 ), the $\mathrm{I}_{25}$-values of all allergens and proteinsugar complexes investigated have been incorporated in one single graph in Fig. 6 .

The hyperbolic curve in Fig. 6 demonstrates that the inhibiting capacity does indeed correlate with the number of sugar-linked lysine residues per molecule, irrespective of the nature of the protein or glycoprotein carrier molecule; in a way, the graph therefore represents a simple dose-response relationship. Insufficient data are on record for the conversion of the $E_{305} / E_{280}$ ratios, as indicative of the structural determinant inactivating the enzyme, into the ratio of blocked lysine to total lysine 
in different atopic allergens. However, the plot of "available" lysine of a series of model conjugates versus the inhibiting capacities (Fig. 5) reveals an inverse relationship and, consequently, a direct correlation exists between the degree of suppression of enzyme activity and the ratio of blocked to total lysine in these model compounds (Table III). For the sake of comparison, some data on atopic allergens, taken from Table II, have been included in Fig. 5, although, of course, this procedure is not strictly allowed.
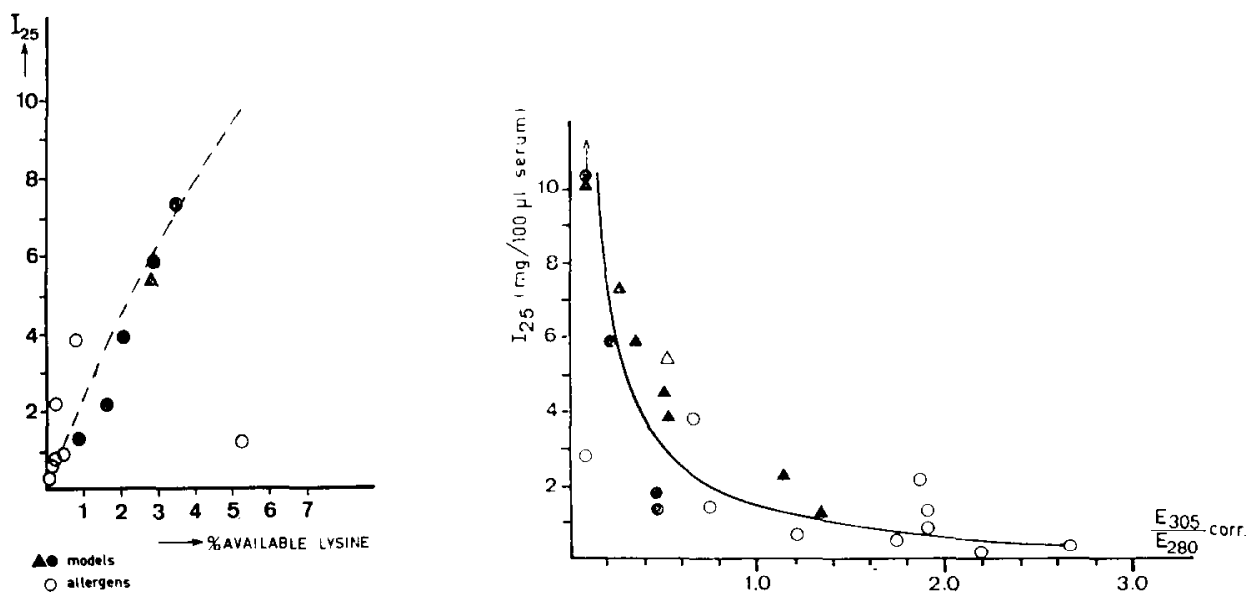

Fig. 5. Inhibiting capacity $\mathrm{I}_{25}$ (mg required for $25 \%$ inhibition of lysyl-2-naphthylamide hydrolysis under standard conditions by $0.1 \mathrm{ml}$ of normal human serum) of some ovalbumin-ribose conjugates (models OVRa-OVRe, •), ovalbumin-glucose conjugate OVG-p (A) and some allergenic substances (0) versus the individual percentages of available lysine. Data taken from Tables II and III.

Fig. 6. Inhibiting capacity $\mathrm{I}_{25}$ (mg required for $25 \%$ inhibition of lysyl-2-naphthylamide hydrolysis under standard conditions by $0.1 \mathrm{ml}$ of normal human serum) of all allergens and highmolecular weight model substances investigated versus the corrected $E_{\mathbf{3 0 5}} / E_{\mathbf{2 8 0}}$ values as estimates of the number of blocked lysine residues in their individual peptide moieties. Data taken from Tables II and III. 0 : allergens (Table II); $\bullet$ : BSA, BSAR, BSAA-a and BSAA-b (Table III); $\triangle$ : ovalbumin-glucose conjugate OVG-p (Table III); $\mathbf{A}$ OVRa-OVRe and OVf-k (Table III).

Identical results were obtained with sera of allergic patients (reaginic sera from house-dust-sensitive patients) as a source of the enzyme, and no significant differences were noted in the $I_{25}$-values of different allergens established with these sera.

\section{d. Other modifiers}

A number of substances were screened for their influence upon lysyl- and arginyl-naphthylamide hydrolysis by human serum. The sulfhydryl blocking agents $N$-ethylmaleimide (NEM), mercurychloride and $p$-hydroxymercury benzoate were found to suppress the enzyme activity almost completely when added to the test system in a final concentration of $\mathrm{IO}^{-2} M$. The $\mathrm{I}_{25}$-value of $\mathrm{NEM}$ was established at I.9 $\mathrm{mg}$ (for $0 . \mathrm{I} \mathrm{ml}$ of serum), which is still considerably above the value obtained with $\mathrm{E} \Lambda \mathrm{C} \Lambda \mathrm{F}$; however, since these experiments were performed with whole serum, an appreciable fraction of the NEM reagent may have reacted aspecifically with other - $\mathrm{SH}$ containing proteins. The metal-chelating agents disodium-EDTA and I, Io-phe- 
nanthroline proved to be very powerful inhibitors, the latter compound inhibiting the lysyl-naphthylamidase completely at $\mathrm{IO}^{-3} \mathrm{M}$. L-Arginine at $\mathrm{IO}^{-3} \mathrm{M}$ suppressed lysyl-2-naphthylamide hydrolysis more effectively than did L-lysine; this suggests that a single enzyme entity is involved in the breakdown of both the lysyl- and arginyl-naphthylamide substrates. The serum naphthylamidase was further effectively blocked with SBTI, less so by ovomucoid (Table II), while Trasylol did not inhibit the enzyme even in final concentrations as elevated as roooo KIE (kallikrein inhibitor units, compare ref. 24). Kraut and Bhargava ${ }^{25}$ have already commented upon the inability of Trasylol to inhibit the enzyme leucine aminopeptidase.

\section{DISCUSSION}

It remains uncertain whether the lysyl- and arginyl-naphthylamidases in human serum represent distinct species of enzymes or whether the hydrolysis of these substrates is mediated by the classical leucine aminopeptidase (E.C. 3.4.I.I.), which is known to be capable of cleaving lysine-arginine bonds ${ }^{26}$. The naphthylamidases studied here certainly share some prominent features with leucine aminopeptidase. Thus, the inhibition by chelating agents suggests the participation of a metal as a cofactor, while the inhibition by NEM, mercury ion, and $p$-hydroxymercury benzoate indicates a sensitive sulfhydryl group. The relative inefficiency of ovomucoid and Trasylol in modifying naphthylamidase action adds to the conclusion that the amino acid hydrolase activity measured in the present work is indeed associated with a peptidase, not with a protease. In a separate series of experiments, atopic allergens were found to inhibit highly purified leucine aminopeptidase from hog kidney and from bovine lens acting upon lysyl-2-naphthylamide, and a similar relationship between the number of blocked lysine residues and the inhibiting capacity as depicted in Fig. 6 was observed for the allergens interfering with the action of these particular enzyme preparations ${ }^{27}$.

The results make it quite plain that the inhibition of serum lysyl- and arginyl naphthylamidases is governed by the lysyl-sugar determinants in the molecular framework of atopic allergens. In accordance, the low-molecular weight model compound EACAF proved a more powerful inhibitor than EACA although, on a molecular basis, it was less effective than atopic allergens or high-molecular weight models. It would be of interest to discover which property of EACAF or of protein-bound lysyl-sugar determinants is responsible for enzyme inhibition. Maillard-type products, like those under investigation (i.e. Schiff bases, their Amadori rearrangement products or the enolic tautomers thereof) are known to exhibit reducing properties, which might cause disruption of disulfide bridges in proteins; also, Schiff bases, and possibly their conversion products, are well-known metal-chelating agents. The observation that both ovalbumin-ribose and ovalbumin-glucose conjugates inhibit lysyl-naphthylamidase would suggest that only the first three or four carbon atoms of the attached sugar residues are involved in the construction of the configuration essential for inhibition, but further work is needed to settle this point.

No different results were obtained with samples of reaginic sera of individuals hypersensitive to one or more of the allergens employed. Also, the level of lysyl-and arginyl-naphthylamidase in the sera of groups of normal and allergic subjects did not differ significantly ${ }^{21}$. The behaviour of these naphthylamidases towards various mod- 
ifiers closely resembles the characteristic pattern of inhibition of bradykininase ${ }^{4}$, but it differs somewhat from aminopeptidase $\mathrm{B}$ isolated from tissues, ${ }^{2,3}$. In this connection, it is worth recalling that leucine aminopeptidase is known to release the $\mathrm{N}$-terminal lysine of kallidin ${ }^{28}$ but is incapable of cleaving the arginine-prolyl bond of bradykinin $^{28}$, a property also ascribed to aminopeptidase $\mathrm{B}^{3}$.

Assuming, in summary, that the lysyl-naphthylamidase is indeed identical to serum kallidinase, it follows from the above considerations that its inhibition by atopic allergens could only be a side-effect of the biological action of allergens in man. However, since the triggering allergen-reagin interaction is considered to operate in atopic individuals only, the interference with the physiological breakdown of kallidin arising in response to this stimulus might conceivably intensify the allergic reaction in sensitized patients.

No attempts have been made to discover a relationship between the inhibiting capacity of atopic allergens (Table II) and their specific activities by skin test in atopic patients (Table I) because this would imply the proposal of one single mechanism of action of diverse allergens on the basis of a common structural (or functional) denominator; also, it would suggest a key role of kininase inhibition in the mechanism of atopic allergy. Prevailing evidence does not support the latter conclusion, while the first propusition at present must remain purely conjectural.

\section{ACKNOWLEDGEMENTS}

The author is indebted to Miss $H$. de Lange for technical assistance and to Mr. W. Bosman for the synthesis of isoxazole. The ovalbumin-aldose conjugates were prepared and analysed by Mrs. W. Nolles-Van Roo and Mr. M. Verborg under the guidance of Dr. E. Bleumink. The generous gifts of Trasylol by N. V. Nedigepha, Amsterdam (Holland) are gratefully acknowledged.

\section{REFERENCES}

I E. Bleumink and L. Berrens, Nature, 2 I 2 (1966) 54 I.

2 V. K. Hopsu, K. K. Mäkinen and G. G. Glenner, Acta Chem. Scand., 20 (1966) i 225.

3 V. K. Hopsu-Havu, K. K. Mäkinen and G. G. Glenner, Nature, 2 I 2 (I966) I 271.

4 F. G. Erdös and E. M. Sloanf, Biochem. Pharmacol, i I (I962) 585.

5 E. G. Erdös, H. Y. T. Yang, L. L. Tague and N. Manning, Biochem. Pharmacol, i6 (1967) I 287 .

6 M. E. Webster and J. V. Pierce, Ann. N.Y. Acad. Sci., I04 (1963) 9 I.

7 G. Ungar and H. Hayashi, $A n n$. Allergy, I6 (I958) 542 .

8 G. Arturson, L. Beckman and B. H. Persson, Nalure, 2 I 4 (1967) I 252.

9 L. Berrens, Intern. Arch. Allergy Appl. Immunol., 29 (I966) 575.

io L. Berrens, Rec. Trav. Chim., 83 (I964) 429.

ir L. Berrens, Intern. Allergy, Appl. Immunol., 34 (rg68) 8r.

i 2 L. Berrens and E. Young, Intern. Avch. Allergy Appl. Immunol., I9 (196r) 34 I.

I3 L. Berrens, J. H. Morris and R. Versie, Intern. Arch. Allergy Appl. Immunol., 27 (1965) i 29.

I 4 L. Berrens, J. H. Morris and E. Young, Dermatologica, i32 (rg66) 433.

I5 D. R. Stanworth, Biochem. J., 65 (I957) 582.

I6 L. BERRENS, Immunochemistry, 4 ( $(\mathrm{Ig} 67) 37$.

17 E. Bleumink, Thesis, Utrecht University, 1967.

I 8 L. Berrens and E. Bleumink, Rec. Trav. Chim., 85 (I966) 59.

19 T. Berrens, Rec. Trav. Chim. 85 (I966) Iit 7.

20 A. R. Justoni, Ital. Patent, 565882 , Aug. I2 (1957); C.A., 53 (1959) 15906 i.

2 I L. Berrens, Clin. Chim. Acta, 20 (1968) I 70.

22 L. Berrens and E. Bleumink, Intern. Allergy Arch. Appl. Immunol., 28 (ig65) I5o. 
23 1). R. Stanworth, Adv an.Immunol., 3 (1963) 18 r.

24 1. Trautschold, E. Werle and G. Zickgraf-Rüdel, Biochem. Phamacol., I6 (1967) 59.

25 H. Kratt and N. Bhargava, Z. Physiol. Chem., 338 (r964) 23 I,

26 R. I. Hill and W. R. Schuidt, J. Biol. Chem., 237 (ig62) 389.

27 L. BERRENS, Nature, 2 I 7 (I968) 664 .

28 I. G. Erdös, A. G. Irenfrew, L. M. Sloane, and J. R. Wohler, Ann. N.X. Acad. Sci., $10+(1963) 222$.

Clin. Chim. Acta, $22(1968) 2.39-2.50$ 